\title{
O Afastamento Paterno após o Fim do Relacionamento Amoroso: Um Estudo Qualitativo
}

\author{
Sabrina Daiana Cúnico" \& Dorian Mônica Arpini \\ Universidade Federal de Santa Maria, Santa Maria, Brasil
}

\begin{abstract}
RESUMO
Este estudo procurou conhecer os motivos que levam alguns pais a abdicar do exercício da paternidade ao final de uma relação conjugal. Para tanto, integraram este estudo cinco pais que participaram da mediação familiar em um Núcleo de Assistência Judiciária e que ao longo dos atendimentos com a equipe de Psicologia demonstraram possuir pouco ou nenhum contato com os filhos. A pesquisa teve caráter qualitativo e foi realizada através de entrevistas semidirigidas de questões abertas. Os resultados alcançados apontaram para a dificuldade que alguns homens possuem de aceitar uma criança proveniente de um momento diferente do considerado por eles como ideal. Além disso, alguns consideraram possuir empecilhos que dificultam o acesso aos filhos, prejudicando assim o exercício da paternidade.
\end{abstract}

Palavras-chave: relações familiares; separação conjugal; ausência paterna.

\section{ABSTRACT \\ The Paternal Remoteness After The End Of a relationship: a qualitative study}

This study aimed to investigate the reasons which lead some fathers to abdicate the paternity at the end of their marital relationship. Five fathers integrated this study and participated in family mediation in a Law Practice Center and that over the appointments with the Psychology team have shown having little or no contact with their children. The research employed a qualitative method, using semistructured interviews with open-ended questions. The results point out the difficulty of some men to accept a child who comes in at a moment not considered by them to be the ideal one. Moreover, some of them mention obstacles which make the access to their children difficult, thus harming the exercise of fatherhood.

Keywords: family relations; marital separation; father's absence.

Cada vez mais, estudos que enfocam o exercício da paternidade vêm sendo realizados (Brito, 2008; Dantas, Jablonski \& Féres-Carneiro, 2004; Gomes \& Resende, 2004; Ramires, 1997; Silva \& Piccinini, 2007; Staudt \& Wagner, 2008). No entanto, a literatura que discorre sobre este tema tende a exaltar os aspectos positivos de tal exercício, reportando a pais que têm disponibilidade e interesse em exercer de fato a paternidade. São escassas, por outro lado, as informações referentes àqueles homens, também pais, cujo interesse pelos filhos não se faz presente. Não obstante à escassez dessas informações, a problemática da ausência paterna não é exclusividade dos tempos modernos, con- forme aponta Corneau (1991), que se baseia no conhecido mito cristão para ilustrar esta afirmação. Segundo ele, o mito central da doutrina católica é marcado pela ausência do pai. José, esposo de Maria, teve sua paternidade negada e participou muito pouco da vida ativa de seu filho Jesus. $\mathrm{O}$ autor afirma ainda que as últimas palavras de Jesus no momento de sua morte, não teriam como ser mais explícitas: "Pai, por que me abandonaste?". Sob este aspecto, entende-se, baseado em Silva (2010), que o mito cristão realmente pode ser representado pela ausência do pai, porém do pai biológico, já que José se apresenta como pai nutridor e afetivo de Jesus, ou seja, pai social.

Endereço para correspondência: Sabrina Daiana Cúnico - sabrinacunico@yahoo.com.br 
Muza (1998) recorre a Freud para destacar a importância da figura paterna como fonte de identificação desde os primeiros momentos da vida do bebê. $\mathrm{O}$ autor pontua que o pai surge na vida da criança como sendo a primeira pessoa que ela encontra fora do ventre da mãe, visto que a criança até então considera que ela e a mãe são a mesma pessoa. Assim, o pai torna-se o terceiro elemento na relação mãe-bebê e acaba por se configurar como um meio de separação entre elas, ou seja, a criança precisa do pai para elaborar a perda da relação inicial com a mãe. Dito de outra forma, o triângulo formado pelo pai, pela mãe e pela criança, deve poder formar-se a fim de substituir a díade mãebebê. Se o pai está ausente, a transferência de identificação da mãe para o pai não acontece, e a criança permanece ligada somente à sua identificação materna. Como o pai tem a função de ser um fator de separação entre a mãe e a criança, introduzindo um princípio de realidade e de ordem de família (Corneau, 1991) torna-se fácil compreender o prejuízo emocional que um pai ausente ou incapaz de assumir a paternidade provoca na criança. Para Dorais (1994), frequentemente faltam modelos positivos de paternidade dentro das famílias. Segundo o autor, a ausência e/ou a indiferença de pais em relação aos seus filhos, explica em grande parte o fato de a masculinidade ser tão malformulada, maltransmitida e mal-assumida pelos homens. Sob essa mesma ótica, Corneau (1991) irá afirmar que "a assinatura do pai ausente se torna a fragilidade da identidade masculina de seus filhos" (p. 47).

A fim de contribuir com as reflexões acerca da paternidade, entende-se fundamental trazer à discussão os quatro modelos de família elucidados por Poster (1979), quais sejam: a aristocrática, a camponesa, a proletária e a burguesa. Destaca-se que, no módulo da família aristocrática, os cuidados da mãe e as relações íntimas e afetuosas entre pais e filhos não eram consideradas importantes e a criação destes era atribuição dos criados e amas de leite. Na família camponesa, percebe-se uma pequena mudança no engajamento das mulheres na criação dos filhos, porém os cuidados dedicados às crianças não eram exclusividade da mãe, que dividia as responsabilidades com demais parentes, pois participava também no trabalho do campo. A família proletária, na qual inicialmente a criação dos filhos era realizada de maneira informal e sem maiores preocupações e atenções, passa por mudanças significativas na segunda metade do século XIX. A família começa a preocupar-se mais com a educação das crianças, tornando-se mais conservadora e incre- mentando a autoridade paterna, de uma forma bem semelhante à dita família burguesa (Poster, 1979). Por fim, na família burguesa, tem-se o homem com a função de prover materialmente a família e a mulher com a responsabilidade pelo cuidado da casa e dos filhos (Poster, 1979; Reis, 2010; Silva, 2010). Uma concepção de família alicerçada na legitimidade, na indissolubilidade, na fidelidade e na autoridade da figura paterna (Silva, 2010).

O que se observa, indo ao encontro do que foi abordado, é que o modelo de pai-provedor, distante dos filhos e representante da autoridade e da lei teve a sua consolidação na família nuclear burguesa ou patriarcal (Ramires, 1997; Reis, 2010; Silva, 2010). É em tal família, na qual há uma rígida divisão de papéis sexuais, que se encontra o padrão de criação de filhos com a exclusão da participação paterna de maneira mais explícita. Padrão este, que ainda parece se estender até os dias atuais, mesmo com os diversos arranjos familiares que estão cada vez mais frequentes (Ramires, 1997). São vários os fatores que contribuíram para o surgimento das distintas configurações familiares que existem atualmente. A maior participação das mulheres no mercado de trabalho, o movimento feminista, o advento dos métodos anticoncepcionais e possibilidade do divórcio foram algumas das situações responsáveis por um processo de mudanças irreversíveis, em que a supremacia masculina na sociedade se viu abalada (Brandão, 2005; Dorais, 1994; Pereira, 2003; Ramires, 1997; Silva, 2010). Pereira (2003) postula que a virada do século XX pode ser caracterizada pela ruptura da ideologia patriarcal, na qual os lugares de pai, mãe e filhos eram claros e bem definidos. Em outras palavras, a família despatrimonializase e perde sua rígida hierarquia de preponderância masculina. Silva (2010) ratifica esta ideia e afirma que os laços entre marido e mulher ou pai e filho, antes sustentados pela autoridade paterna, passam agora a serem embasados muito mais pela intimidade e pelo vínculo do que pela tradição. Para Pereira (2003), no entanto, com o declínio desta estrutura patriarcal, os lugares que eram antes bem acentuados, ficaram alterados, o que provocou importantes consequências na formação das famílias atuais, sendo o empobrecimento da vinculação dos homens com a paternidade uma das consequências mais relevantes.

Em situações de separação e/ou divórcio, é sabido que, na grande maioria dos casos, as mães levam vantagem no que diz respeito à guarda dos filhos do casal 
(Brito, 2008; Hurstel, 1999; Muzio, 1998). Muzio (1998) salienta que o fato de a mulher ainda ser considerada como sendo portadora de um instinto materno, acaba contribuindo para que a paternidade seja representada socialmente como um papel secundário e menos prioritário para o desenvolvimento dos filhos. Inevitavelmente, a variação de dinâmicas e arranjos familiares teve repercussão no desempenho dos papéis parentais (Diniz Neto \& Féres-Carneiro, 2005; Dorais, 1994; Grzybowski, 2002; Pereira, 2003). Neste sentido, Dorais (1994) afirma que as famílias desfeitas, monoparentais, recompostas, dentre outras, estão mudando completamente o próprio conceito de paternidade. Sendo assim, o laço biológico não garante mais a ligação permanente entre pais e filhos, sendo que diversos pais que não obtêm ou não desejam a guarda dos filhos acabam por se ausentar definitivamente da vida destes. Por outro lado, à medida que as famílias recompostas se multiplicam, os homens passam a manter relações parentais com os filhos da atual companheira, crianças com as quais não possuem laços biológicos (Dorais, 1994) dando início ao exercício de uma paternidade social, isto é, uma paternidade na qual os vínculos estabelecidos são amparados, especialmente, por laços afetivos (Warpechowski \& Mosmann, 2012).

Considerando que a família nuclear não ocupa mais o espaço hegemônico que ocupava outrora, ainda que este modelo permaneça no imaginário social como ideal de família, outros modelos familiares se fazem presentes atualmente como as famílias homoafetivas, famílias recompostas, famílias monoparentais, dente outros (Fonseca, 2002; Kehl, 2003). Em concordância com este entendimento, Fonseca (2002) aponta para a importância de se ter um olhar ampliado no que diz respeito às relações familiares na contemporaneidade, em especial no que tange a complexidade do desempenho dos papéis parentais em diferentes contextos sócio culturais. Nesse sentido, Dorais (1994) entende que são três os grandes desafios da paternidade atualmente. $\mathrm{O}$ primeiro consiste em garantir às crianças de hoje a constância de figuras paternas, tendo em vista as diversas mudanças familiares e sociais ocorridas. O segundo é adaptar a vida dos homens à paternidade, desmistificando a ideia de que o homem é em primeiro lugar um trabalhador e em segundo um pai. Por fim, o terceiro desafio é em relação às técnicas de reprodução assistida, que suscitam ainda inúmeras questões éticas.

Diante do que foi exposto, entende-se ser necessário fomentar a discussão a respeito da ausência paterna no cenário familiar. Para tanto, realizou-se uma pesquisa de caráter qualitativo com o objetivo de conhecer, através do ponto de vista dos pais, os possíveis motivos que os levam a abdicar do exercício da paternidade ao final da relação conjugal.

\section{MÉTODO}

\section{Participantes}

Integraram este estudo cinco pais, na faixa etária entre 21 e 41 anos, que participaram do serviço de Mediação Familiar em um Núcleo de Assistência Judiciária $^{1}$ de uma instituição pública de ensino superior e que aceitaram participar desta pesquisa. Todos eles, ao longo dos atendimentos com o serviço de Psicologia - atendimentos que precederam à Mediação mostraram ter uma relação distante com o(s) filho(s). Destaca-se que o Núcleo de Assistência Judiciária concentra as suas atividades jurídicas prioritariamente nas áreas do Direito Processual Civil e Direito de Família, atendendo a uma população com renda mensal de até três salários mínimos.

Dentre estes cinco participantes, encontram-se tanto pais com filhos provenientes de apenas uma relação conjugal quanto pais de crianças de mais de um relacionamento amoroso. Nestes casos, a entrevista focou o relacionamento com o filho no qual o acordo realizado no Núcleo de Assistência Judiciária se baseou. Ressalta-se que nenhum dos participantes foi legalmente casado com a mãe da criança, sendo que quatro deles se separaram antes mesmo do nascimento do filho. Na tabela a seguir, apresentam-se outras informações relevantes de cada participante. 
Tabela 1

Caracterização dos Participantes

\begin{tabular}{cccccc}
\hline Pai & Idade & Profissão & Filhos & Idade dos filhos & Tempo de separação \\
P1 & 41 & Motorista & 1 & 09 anos & 09 anos e meio \\
P2 & 21 & Desempregado & 2 & $\begin{array}{c}01 \text { ano e } 04 \text { meses* } \\
\left(1^{\circ} \text { relação }\right)\end{array}$ & 02 anos \\
& & & & 09 meses (relação atual $)$ & \\
P3 & 28 & Coletor & 4 & $\begin{array}{c}09 \text { e } 08 \text { anos }\left(1^{\circ} \text { relação }\right) \\
\left.02^{\circ} \text { relação }\right)\end{array}$ & 04 anos \\
P4 & 33 & Motorista & 1 & 04 anos & 04 anos \\
P5 & 22 & $\begin{array}{c}\text { Auxiliar de } \\
\text { limpeza }\end{array}$ & 1 & 02 anos & 01 ano \\
\hline
\end{tabular}

* filhos a quem a entrevista se referiu

\section{Instrumentos}

Esta pesquisa teve caráter qualitativo, tendo sido realizada por meio de entrevistas semidirigidas de questões abertas. Para Turato (2003) este tipo de entrevista se caracteriza como sendo uma troca dinâmica de direção, dada ora pelo entrevistador ora pelo entrevistado, facilitando a coleta de informações baseada no discurso livre do entrevistado através da introdução de tópicos pelo entrevistador.

\section{Procedimentos}

O contato inicial com estes pais se deu através de ligação telefônica, através da qual foi feito o convite para que participassem da pesquisa. A entrevista foi agendada de acordo com a disponibilidade de cada participante. Todas as entrevistas ocorreram no Departamento de Psicologia da referida instituição de ensino por se tratar de um lugar "neutro", já que realizá-las no local de práticas jurídicas poderia intimidar os participantes ou fazer com que confundissem a entrevista com as demandas apresentadas ao Núcleo de Assistência Judiciária, interferindo assim no objetivo do estudo.

Todos os sujeitos da pesquisa receberam, antes do início da entrevista, uma cópia do termo de consentimento livre e esclarecido, por meio do qual ficaram cientes dos objetivos do estudo bem como sobre o compromisso dos pesquisadores com a confidenciali- dade dos dados, assinando-o e autorizando a sua participação na pesquisa.

Ressalta-se que esta pesquisa está respaldada nas Diretrizes e Normas Regulamentadoras de Pesquisa envolvendo Seres Humanos (Resolução 196/96 do Conselho Nacional de Saúde) e na Resolução ${ }^{\circ}$ 016/2000 do Conselho Federal de Psicologia. Este projeto foi aprovado pelo Comitê de Ética da Universidade pública de ensino superior que as pesquisadoras estão vinculadas, sob o número 23081.005766/ 2011-94.

\section{Análise de dados}

As cinco entrevistas realizadas foram gravadas e posteriormente transcritas na íntegra e a análise dos dados foi obtida a partir dessa transcrição. A análise foi qualitativa, utilizando-se a análise de conteúdo proposta por Bardin (1977). Foi realizada a leitura e a análise individual de cada entrevista transcrita, através da qual foram identificados os aspectos frequentes, por meio da carga afetiva contida na fala e/ou pelas repetições, de cada uma delas.

Após, identificou-se aspectos comuns entre as falas dos entrevistados e realizou-se o agrupamento destes temas em tópicos, que foram posteriormente elencados em categorias a fim de promover o melhor entendimento sobre os dados obtidos. As categorias foram analisadas a luz de teorias que discorrem sobre o tema e através de vinhetas ${ }^{2}$ retiradas das próprias entrevistas. 


\section{RESULTADOS E DISCUSSÃO}

Os resultados serão apresentados de acordo com as categorias identificadas: 1 . O ideal da paternidade e 2 . Obstáculos ao exercício da paternidade.

\section{- O ideal da paternidade}

\subsection{Momento ideal}

Sabe-se que a decisão de ter um filho não é fácil e que envolve vários fatores. Em muitos casos, o casal decide em conjunto, considerando a sua ideia de projeto futuro e as suas pretensões para a vida a dois. No entanto, por inúmeras razões, nem sempre a gravidez é planejada, o que faz com que o filho nasça antes de surgir o desejo de o ter.

"[...] porque até eu nem queria, né? Mas, como aconteceu, né? A criança não tem culpa, né?"' (P2)

"No momento assim, era uma coisa que eu não queria... mas depois foi passando o tempo, aí fui aceitando, tinha que aceitar né?"'(P4)

Nota-se certa resignação nas falas destes homens ao mencionar a sua aceitação da paternidade. Enquanto um (P2) diz que a criança não tem culpa, outro (P4) afirma que a sua aceitação lhe foi imposta, na medida em que a gravidez já estava confirmada, o que ele deixa claro quando diz que não teve escolha, que teve de aceitar. Nesta perspectiva, Corso e Corso (2011) salientam que muitos casos de parentalidade fragilizada proveem de relacionamentos que iniciam a partir de uma gravidez, sobre a qual não se havia feito nenhum plano em conjunto entre o casal. Ou seja, relacionamentos que tiveram início a partir de uma gestação, sem que houvesse uma trajetória antecedente, nem que seja mínima, deste casal, que nunca compartilhou qualquer tipo de projeto ou sonho e que agora será pai e mãe.

Outro ponto evidenciado é que, para os participantes desta pesquisa ter sido pai num período diferente do que o período por eles imaginado, gerou um sentimento de insegurança, ou seja, sentiram-se "perdidos" perante a nova situação, como se pode perceber pelos recortes abaixo:

"Fiquei meio... perdido [risos] brabo um dia inteiro, mas depois passa né? Mas, tranquilo..." (P2)

"É... pelo um certo lado feliz, é um desejo de todo homem e toda mulher né? É ter um filho. Mas, como eu te falei, eu acho que não era bem certo o momento... pelo um lado tinha uma felicidade e pelo um lado eu fiquei meio... é... cabisbaixo, meio perdido, vamos dizer assim" (P1)

O que se observou neste estudo é que a ausência de um projeto de paternidade decorrente desta relação conjugal pode ter dificultado a aceitação da paternidade no momento em que ela se revelou, uma vez que se sabe que o anseio pela paternidade não é inerente ao momento em que a gravidez é descoberta, percepção compartilhada por Padilha (2008) que entende que o amor paterno e a vontade de ser pai não são inerentes ao homem.

Neste tocante, Corso e Corso (2011) pontuam que a condição irreversível da paternidade é o que a torna tão assustadora para os homens que não estão preparados para lidar com ela. Os autores afirmam que para a mãe, o uso de seu corpo ao longo da gestação por aquele filho já a convence de que esta criança passará a ocupar espaço para sempre em sua vida. Já o pai, em contrapartida, irá descobrindo isto aos poucos e, para muitos, se descobrir eternamente ligado a um filho que ignora, renega ou nunca desejou pode dificultar o estabelecimento de um vínculo afetivo entre pai e filho.

Em síntese, a ideia que considera a existência de um contexto ideal para a concepção de uma criança parece ter sido incorporada pela maior parte dos participantes desta pesquisa. Situações como gravidez não planejada, instabilidade financeira e a vontade de não ter compromisso sério com a mãe da criança foram algumas das situações citadas por estes pais para justificarem as suas afirmações de que o filho em questão não veio no momento certo. Curiosamente todos eles são, ainda hoje, pais ausentes e que mantém pouco ou nenhum contato com seus filhos, o que pode ser constatado pelas falas a seguir:

"Não tenho nem contato! Nem com ela [referindo-se a mãe de seu filho], nem com ele [referindo-se ao seu fi1ho], quem tem é meu pai... e a minha irmã, que eles vão lá né? Que eu pago a pensão, dou tudo pra eles e eles vão lá, levam, e eu não... não tenho nem contato com eles" (P4)

“[...] daí faz até um bom tempo já que eu não vejo ele, quase um ano já que eu não vejo ele..." (P1)

“[...] até porque ele teve na minha casa... 03 vezes, mais ou menos, em todo esse tempo, 03 vezes..." [referindo-se 
ao número de vezes em que o filho de 04 anos esteve em sua casa] (P3)

Percebe-se, pelo depoimento destes pais que a ausência da situação ideal impossibilitou-os de construírem um vínculo satisfatório com os filhos, razão pela qual se pode pensar que não há um investimento afetivo na relação entre pai e filho, cumprindo-se apenas as formalidades prescritas em lei, como por exemplo, o pagamento da pensão alimentícia. Tal afirmação remete à preocupação, já sinalizada por Pereira (2003), com o abandono psíquico dos pais em relação aos filhos e suas consequências, na medida em que muitos deles apresentam dificuldades no cumprimento da visitação, uma vez que esta implica a construção de um vínculo que envolve o comprometimento afetivo, o qual não se pode prescrever em lei.

\subsection{Pai provedor}

Seguindo neste contexto, pode-se verificar a partir do extrato seguinte que, para alguns homens, a decisão de ter um filho está diretamente relacionada com a estabilidade financeira:

"E... claro que me abalou, porque... eu não queria... no caso um filho, [...] eu achava que não era o momento certo [...] se eu fosse a vir a ficar com ela, eu queria ter uma estabilidade para ter um filho... né? Pra dar do bom e do melhor pro filho pelo menos... E ficou meio... meio abalado, vamos dizer assim, a nossa relação quando, quando eu soube que ela estava grávida" (P1)

O participante acima (P1) relata que gostaria de ser pai somente quando pudesse sustentar e proporcionar uma vida confortável para a criança, remetendo à ideia de que a função principal da paternidade é prover materialmente a esposa e os filhos (Hurstel, 1999; Padilha, 2008; Ramires, 1997, Reis, 2010; Roudinesco, 2003; Silva, 2010). Destarte, este homem, não tendo a possibilidade de dar "do bom e do melhor pro filho", sentiu-se impossibilitado de ser pai, em termos afetivos. Neste sentido, Padilha (2008) afirma que "se o lugar do homem não é o de cuidador, é na dimensão econômica que a paternidade é socialmente reconhecida e valorizada" (p.193).

Na verdade, neste estudo, evidenciou-se certa similaridade entre os participantes no que diz respeito à relação filho-dinheiro. Vários pais mencionaram a sua (frágil) situação financeira para justificar a sua reação (negativa) perante a notícia de que iriam ser pais. As falas abaixo ilustram esta afirmação:
"Ah, eu me senti arrasado até porque eu não queria, naquele momento eu não tinha... condições financeiras, [...] pra ter mais um filho onde eu não ia poder dá atenção, dá ajuda financeira e mesmo que eu não queria, não pela criança, [...] eu não queria ter compromisso com ela então por isso eu não queria ter filhos." (P3)

“Assustado! Bem assustado... não tava trabalhando de carteira assinada ainda, nem nada, só... biscate mais né.. .e ela também não tava trabalhando, foi... difícil, foi uma época difícil...". (P5)

De acordo com Costa (1989), um dos traços mais fortes da identidade psicológica masculina é a noção de trabalhador. Ou seja, para muitos homens ser bom trabalhador é o mesmo que ser bom pai, bom marido, bom filho, etc. Isto talvez explique a evidente preocupação dos participantes com a sua condição financeira no momento em que souberam que iam ser pais, pois seria esta condição que supostamente qualificaria o seu exercício da paternidade.

Conforme exposto, a visão de que a função paterna principal é sustentar financeiramente a família ainda é predominante no contexto social e povoa o imaginário de muitos homens. Tal afirmação vai ao encontro dos achados de Bustamante (2005) que ao realizar um estudo de cunho etnográfico com famílias de camadas populares evidenciou que o papel de provedor era visto pelos homens como o mais importante componente da paternidade. Sendo assim, diante da falta de recursos financeiros para sustentar os filhos, os pais tendiam a se afastar, deixando de assumir também outras funções.

\section{- Empecilhos ao exercício da paternidade}

\subsection{Casal parental $x$ casal conjugal}

É sabido que, mesmo nos casos em que o divórcio é a melhor solução para um casal, ele poderá ser vivenciado como uma situação dolorosa e estressante, gerando sentimentos de fracasso, impotência e perda em ambos os cônjuges (Féres-Carneiro, 1998). Contudo, entende-se que a separação matrimonial não deve ser responsável pela dissolução dos vínculos entre pais e filhos, visto que as problemáticas envolvendo o relacionamento conjugal não devem ser deslocadas para as funções parentais (Brandão, 2005).

Sob este mesmo viés, Féres-Carneiro (1998) aponta para a importância de que o casal em processo de separação conjugal se esforce para deixar os filhos de 
fora do conflito, visto que quem divorcia é o casal conjugal e não o casal parental, que deve continuar sempre com as funções de cuidar, proteger e prover as necessidades dos filhos. As falas seguintes indicam claramente a dificuldade que alguns pais parecem ter em separar os conflitos envolvendo a relação conjugal desfeita com o exercício da paternidade. É evidente que este participante (P5) tem uma relação conflituosa com a família da sua ex-companheira. Neste contexto, a solução que encontrou para fazer face ao problema foi o afastamento, ainda que este implique não poder conviver também com o seu filho.

"Eu não vou lá porque é muita fofoca e coisa, porque eu podia, tipo... meia hora só aparecer lá no meu intervalo, podia...só que lá naquela rua, eles vê um negócio e inventam um monte de coisa também, daí eu não... me desanima um pouco" (P5)

"Eu vi ele no acaso, foi lá no hospital mesmo, que ele tava fazendo consulta, ai depois eu não... não quis ir lá... enquanto a mãe dela tava de férias, eu não ia lá... [...] ela [referindo-se à mãe do seu filho] só fala que eu não sou pai, não sei o que, que se eu fosse pai eu tava mais junto... dai eu falei pra ela bah, e de que adianta ficar bastante tempo e coisa sendo que depois eu viro as costas, tão falando de mim', dai eu disse 'imagina se fosse tu no meu lugar, se tu ia gostar disso, mesma coisa, tu queria não aparecer mais" (P5)

Em relação aos participantes deste estudo, a maioria alegou possuir obstáculos que dificultam o seu acesso às crianças e que acabam por contribuir para que não tenham uma relação mais estreita com elas. A difícil relação com a mãe das crianças e/ou com a família desta foram as situações mais apontadas.

A respeito disto, Dantas et al. (2004) salientam que a dificuldade em lidar com a separação devido a toda a carga emocional que este processo envolve, pode contribuir para que as mães dificultem, efetivamente, o contato entre pais e filhos. Ainda que nenhum dos pais entrevistados tenha sido legalmente casado com a ex-companheira e que a relação conjugal não tenha sido de ampla duração, percebeu-se que a relação estabelecida entre o ex-casal após o fim da relação provoca interferências no modo como eles exercem a parentalidade pós-dissolução.

"A minha mãe não conhece o meu filho, os meus familiares praticamente não conhecem o meu filho por causa dela [...] ela me impede e outra que acho que desde pequeno ela tipo manipulou o guri, tu entendeu? A criança já criou com aquilo, só da mãe, só da mãe [...]" (P1)
"O motivo... é de eu não vê ele mais em seguida, eu acredito eu que é isso [referindo-se à difícil relação que tem com a ex-sogra]. Até já conversei com ela [referindo-se à ex-companheira] [...] ela também acha que é isso, quando ele me estranha e coisa... acho que é mais de eu vê ele, pegar ele e vê ele mais... mas, tem umas atitudes lá que eu não... eu não aceito, da família dela dai eu não procuro... me expor demais" (P5)

"Eu vi... agora acho que faz... uma semana acho porque esses dias eu tive lá levando a pensão dele, mas antes disso já fazia 04 mês que eu não via ele... nesse acordo que a gente tem eu posso vê ele 02 vez né, no mês, mas é que... eu evito até mesmo de ir... porque toda vez que eu vô, ela toca no mesmo assunto de por que que eu escolhi a outra, a vizinha dela ao invés de ter vivido com ela [...]" (P3)

Diferentemente dos demais pais, o participante P3 admite que sua ausência na vida do filho se deve muito mais a uma escolha sua do que a algum impedimento por parte da mãe da criança. Pelo fato de não querer conviver com as problemáticas que envolvem o relacionamento conjugal desfeito, este pai se afasta, o que acaba por fragilizar o exercício de sua paternidade. Brandão (2005), indo ao encontro da situação exposta, afirma que alguns progenitores acabam por desaparecer da vida dos seus filhos, justamente por não suportarem os constantes desentendimentos com o ex-cônjuge, ou não aceitarem o papel de meros visitantes a que são designados.

Dos cinco pais entrevistados neste estudo, três deles possuíam um acordo que contemplava a livre visitação dos filhos, ou seja, estes pais poderiam vê-los sempre que assim o desejassem. No entanto, conforme relatos, as visitas raramente ocorriam. Bruno (2003) salienta que nem sempre a livre visitação irá atender às necessidades fundamentais dos filhos no que diz respeito à manutenção do contato com ambos os genitores.

Uma das causas é que não ter esquema de visitas previsto em lei e não ter os filhos cotidianamente consigo pode fazer com que o genitor que não detém a guarda reorganize a sua rotina após a separação conjugal não prevendo espaço para a prole, tendo como consequência pouco ou nenhum contato com eles (Bruno, 2003). Assim, pode-se pensar que a livre visitação é indicada somente nos casos em que ambos os genitores possuem o desejo de convivência com os filhos, o que talvez não seja o caso dos participantes aqui entrevistados. 
Por fim, considera-se relevante expor que, ainda que os participantes deste estudo apresentem como justificativas as dificuldades de relacionamento que têm com a mãe ou avó do seu filho, é de salientar que, se eles realmente desejassem exercer a paternidade, poderiam ter recorrido ao Núcleo de Assistência Judiciária - local onde, através da mediação familiar, se estabeleceu o acordo incluindo a regularização das visitas - com o objetivo de informar que o acordo não estava sendo cumprido pela ex-companheira, procurando, assim, auxílio para ultrapassar os obstáculos.

\subsection{Novos relacionamentos $X$ novos conflitos}

Outra situação relatada pelos participantes, também considerada por eles como um empecilho para o exercício da paternidade, foi a dificuldade de aceitação por parte da atual companheira de que o contato entre pai e filho se mantenha. Tal constatação vai ao encontro do que postula Soares (2008) que afirma que o afastamento do pai após o rompimento conjugal pode ser intensificado com a constituição de uma nova família por parte deste pai e prováveis filhos dessa união.

"[...] ela [referindo-se à ex-companheira] se junta muito com pessoas que falam demais, inventam histórias, então se eu for lá e pegar já dizem que eu to correndo atrás dela, to me encontrando com ela e... a minha esposa acredita muito nessas coisas... ela é muito ciumenta, ela também não aceita muito meus filhos, nenhum deles, mas o que ela mais aceita é o $X$, por incrível que pareça, é a única criança que eu mais fico longe, por vontade própria $[\ldots](\mathrm{P} 3)$

De acordo com este participante, uma das principais razões que faz com que ele não mantenha um contato mais estreito com o seu filho é o ciúme que sua atual esposa possui de suas relações passadas e os filhos provenientes destas relações. De fato, para alguns pais, se ausentar totalmente da vida de seus filhos de relações anteriores é encarado como uma prova de amor e dedicação para com o novo relacionamento (Corso \& Corso, 2011). No entanto, o que mais chama a atenção é quando este pai diz que "é a única criança que eu mais fico longe, por vontade própria". Este participante possui 4 filhos de 3 relações diferentes, porém, não parece conseguir se posicionar afetivamente como pai desta criança em razão de não estar disposto a manter nenhum tipo de relação com a mãe do menino.
A situação deste pai parece ilustrar a ideia de Corso e Corso (2011) que afirmam que muitos casais após a separação conjugal atuam no sentido de anular a experiência familiar anterior, em uma tentativa de fundar a primeira família novamente. Desta forma, excluem-se da vida dos filhos oriundos da antiga relação, inclusive afetivamente, por serem a lembrança de um passado que não gostariam de lembrar.

\subsection{Falta de tempo X ausência de desejo}

Nesta pesquisa, para além das dificuldades que envolvem a relação conjugal desfeita, o "tempo" também foi apontado pelos participantes como sendo um obstáculo frente ao exercício da paternidade. Com efeito, como se pode constatar a seguir, a "falta de tempo" surge como um dos fatores que mais impede um convívio mais próximo com os filhos.

"[...] na época eu te disse que eu trabalhava muito, quase que o dia inteiro, eu trabalhava e cansava muito, né?" (P1)

"[...] lá... na safra assim é corrido né? Sábado e domingo, direto. Aí não tem como... só de noite, né? Mas, de noite eu não vou tá indo na casa dos outros, fica chato." (P2)

Ao analisarmos as falas citadas, pode-se inferir que mais do que a falta de tempo, que estes pais dizem ter, existe uma falta de desejo, por parte destes, de querer conviver mais com os seus filhos. O participante $\mathrm{P} 2$, por exemplo, alega que só tem tempo livre à noite $\mathrm{e}$ que não considera prudente ir visitar seu filho a essa hora. É em tal contexto que Dolto (1989/2011) irá sustentar que as relações de afetividade ficam desumanizadas ao serem determinadas pelos dias de semana e não pelas afinidades. Assim sendo, o termo regulamentação de visitas não contempla o que há de vivo e afetivo entre pais e filhos. Tais considerações também são apontadas nos estudos de Brito (2008) e Soares (2008).

Esta situação evidencia a preocupação já sinalizada por diversos autores (Brandão, 2005; Brito, 2008; Bruno, 2003; Dolto, 1989/2011) de que a definição de um genitor guardião e um genitor visitante faz com que muitos pais que não detém a guarda dos filhos acreditem que devam se manter à distância destes por considerarem que a Justiça dá plenos poderes ao detentor da guarda. Além disso, alguns pais podem equivocadamente interpretar a sua condição de visi- 
tante, achando que não lhes cabe preocupações com o dia a dia do filho.

"[...] uma vez só eu conversei com ele [referindo-se ao filho] sobre não tá indo lá que... na época eu soltava muito tarde, trabalhava até os finais de semana [...]... daí expliquei pra ele que eu soltava muito tarde, eи não tinha como vê ele e nos finais de semana eu também jogo bola, jogo futebol né, e... por isso eu não ia vê muito ele" (P3)

Nesta mesma direção, o participante acima afirma que no seu tempo livre possui outros compromissos como o jogo de futebol que o impedem de visitar o filho com mais frequência. No entanto, não parece considerar a hipótese de que seu filho o acompanhe nos seus momentos de lazer, fazendo com que os dois passem mais tempo juntos. Ou seja, neste caso, também se poderia pensar que é a ausência de desejo que motiva a ausência de tempo.

Vale mencionar que, ao se avaliar se a visitação deve ser livre ou ter regulamentação, é necessário considerar a situação de cada contexto familiar. Como apontado anteriormente, para alguns participantes deste estudo, a livre visitação - que pode parecer ideal num primeiro momento - não se efetivou e acabou contribuindo para um descomprometimento com a relação parental por parte destes pais. Tal situação leva a pensar que nesses casos seria interessante considerar a regulamentação de visitas na tentativa de aproximar a relação paterno-filial.

Perante tudo o que foi exposto, identificam-se facilmente vários obstáculos que podem dificultar o exercício da paternidade por parte destes pais. Situações como a relação conflituosa com a excompanheira, com a família desta e a falta de tempo foram citadas como sendo empecilhos para que estes pais passem mais tempo junto de seus filhos. O que se observa, contudo, é que alguns homens pouco ou nada fazem para reverter esta situação, muitas vezes criadas por eles próprios, devido a uma impossibilidade de exercer de fato a paternidade afetiva dessas crianças.

\section{CONSIDERAÇÕES FINAIS}

O presente artigo se propôs a abordar a problemática da ausência paterna após situações de separação conjugal, levando em conta os discursos que os próprios pais mobilizam para justificar a sua ausência. Pôde-se constatar que a paternidade ou o desejo dela não depende somente da existência de um genitor e uma criança, ou seja, ser pai pressupõe o estabelecimento de um vínculo afetivo com os filhos para além da filiação biológica. Entende-se que, ainda que os sujeitos desta pesquisa tenham alegado motivos como a falta de tempo ou a má relação com ex-companheira e/ou a família desta para justificar a pouca relação que mantém com os filhos, a principal causa deste afastamento parece ser decorrente de uma impossibilidade em posicionar-se afetivamente frente a estas crianças. Impossibilidade esta que parece estar diretamente relacionada a uma gestação num momento não considerado como ideal e que não foi acompanhada de um projeto de paternidade pelo casal conjugal.

Nesse sentido, considerando a perspectiva histórica, pode-se pensar que os homens permitem-se afastar-se do convívio com os filhos que não tenham desejado por compreender que a mãe é naturalmente mais apta aos cuidados da prole, sobretudo nos aspectos que envolvem afetividade. Tal perspectiva histórica pode dar margem também a ideia de que a ação paterna seria complementar e periférica, sendo prioritária apenas quando se trata da questão financeira.

Não se pretendeu com este estudo fazer generalizações no sentido de contemplar toda a problemática envolvendo a ausência paterna no ambiente familiar. No entanto, entende-se que esta pesquisa pôde contribuir para uma maior reflexão acerca desta questão. Por fim, destaca-se a importância de se construir espaços de escuta, nos quais os casais em processo de separação, principalmente nos casos em que o casal tem filhos, possam trabalhar as relações, dando oportunidade para uma valorização do lugar do pai no cenário familiar. Entende-se que tal escuta poderia ser também de grande valia para pais e mães que tenham preocupações com relações aos cuidados parentais e que se encontrem em dificuldades. Estes espaços poderiam abrandar os problemas e as dificuldades do exercício da paternidade ao final de uma relação conjugal, considerando a importância já reconhecida do lugar do pai na vida dos filhos.

\section{REFERÊNCIAS}

Bardin, L. (1977). Análise de conteúdo (L. A. Reto \& A. Pinheiro, Trans.). Lisboa: Edições 70.

Brandão, E. P. (2005). A interlocução com o Direito à luz das práticas psicológicas em Varas de Família. In H. S. Gonçalves 
\& E. P. Brandão (Eds.), Psicologia jurídica no Brasil (pp. 5197). Rio de Janeiro: NAU.

Brasil. (1996). Ministério da Saúde. Resolução 196/96 - Diretrizes e Normas Regulamentadoras de Pesquisas envolvendo Seres Humanos. Brasília-DF.

Brito, L. M. T. (2008). Alianças desfeitas, ninhos refeitos: Mudanças na família pós-divórcio. In L. M. T. Brito (Ed.), Famílias e separações: Perspectivas da psicologia jurídica (pp. 1747). Rio de Janeiro: UERJ.

Bruno, D. D. (2003). Direito de visita: Direito de convivência. In G. C. Groeninga \& R. C. Pereira (Eds.), Direito de família e psicanálise: Rumo a uma nova epistemologia (pp. 311-324). Rio de Janeiro: Imago.

Bustamante, V. (2005). Ser pai no subúrbio ferroviário de Salvador: Um estudo de caso com homens de camadas populares. Psicologia em Estudo, 10, 393-402.

Conselho Federal de Psicologia. (2000). Resolução 16/00 - Realização de Pesquisa em Psicologia com Seres Humanos. Brasília-DF.

Corneau, G. (1991). Pai ausente, filho carente: O que aconteceu com os homens? (L. Jahn, Trans.). São Paulo: Brasiliense.

Corso, D. L., \& Corso, M. (2011). A psicanálise na Terra do Nunca: Ensaios sobre a fantasia. Porto Alegre: Penso.

Costa, J. F. (1989). Psicanálise e contexto cultural: Imaginário psicanalítico, grupos e psicoterapias. Rio de Janeiro: Campus.

Dantas, C., Jablonski, B., \& Féres-Carneiro, T. (2004). Paternidade: Considerações sobre a relação pais-filhos após a separação conjugal. Paideia, 14, 347-357.

Diniz Neto, O., \& Féres-Carneiro, T. (2005). Psicoterapia de casal na pós-modernidade: Rupturas e possibilidades. Estudos de Psicologia, 22, 133-141.

Dolto, F. (2011). Quando os pais se separam (V. Ribeiro, Trans.). Rio de Janeiro: Zahar. (Original publicado em 1989)

Dorais, M. (1994). O homem desamparado (Y. M. C. T. Silva, Trans.). São Paulo: Loyola.

Féres-Carneiro, T. (1998). Casamento contemporâneo: O difícil convívio da individualidade com a conjugalidade. Psicologia Reflexão e Crítica, 11, 379-394.

Fonseca, C. (2002). Mãe é uma só? - Reflexões em torno de alguns casos brasileiros. Psicologia USP, 13, 49-68.

Grzybowski, L. S. (2002). Famílias monoparentais - Mulheres divorciadas chefes de família. In A. Wagner (Ed.), Família em cena-Tramas, dramas e transformações (pp. 39-53). Petrópolis: Vozes.

Gomes, A. J. S., \& Resende, V. R. (2004). O pai presente: O desvelar da paternidade em uma família contemporânea. Psicologia: Teoria e Pesquisa, 20, 119-125.
Hurstel, F. (1999). As novas fronteiras da paternidade (E. E. C. de Castro, Trad.). Campinas: Papirus.

Kehl, M. R. (2003). Em defesa da família tentacular. In G. C. Groeninga, \& R. C. Pereira (Eds.), Direito de família e psicanálise: Rumo a uma nova epistemologia (pp. 163-176). Rio de Janeiro: Imago.

Muza, G. M. (1998). Da proteção generosa à vítima do vazio. In P. Silveira (Ed.), O exercício da paternidade (pp. 143-150). Porto Alegre: Artes Médicas.

Muzio, P. A. (1998). Paternidade (ser pai)... Para que serve? In P. Silveira (Ed.), O exercício da paternidade (pp. 165-174). Porto Alegre: Artes Médicas.

Padilha, C. C. (2008). Quando o pai vira réu por alegação de abandono afetivo. In L. M. T. Brito (Ed.), Famílias e separações: Perspectivas da psicologia jurídica (pp. 187-217). Rio de Janeiro: UERJ.

Pereira, R. C. (2003). Pai, por que me abandonaste? In G. C. Groeninga \& R. C. Pereira (Eds.), Direito de família e psicanálise: Rumo a uma nova epistemologia (pp. 219-228). Rio de Janeiro: Imago.

Poster, M. (1979). Teoria crítica da família (A. Cabral, Trans.). Rio de Janeiro: Zahar.

Ramires, V. R. (1997). O exercício da paternidade hoje. Rio de Janeiro: Rosa dos Tempos.

Reis, E. F. (2010). Varas de família - Um encontro entre psicologia e direito. Curitiba: Juruá.

Roudinesco, E. (2003). A família em desordem (A. Telles, Trans.). Rio de Janeiro: Zahar.

Silva, J. M. (2010). O lugar do pai: Uma construção imaginária. São Paulo: Annablume.

Silva, M. R., \& Piccinini, C. A. (2007). Sentimentos sobre a paternidade e o envolvimento paterno: Um estudo qualitativo. Estudos de Psicologia, 24, 561-573.

Soares, L. C. E. C. (2008). A família com padrasto e/ou madrasta: Um panorama. In L. M. T. Brito (Ed.), Famílias e separações: Perspectivas da psicologia jurídica (pp. 81-112). Rio de Janeiro: UERJ.

Staudt, A. C. P., \& Wagner, A. (2008). Paternidade em tempos de mudança. Psicologia: Teoria e Prática, 10, 174-185.

Turatto, E. R. (2003). Tratado de metodologia da pesquisa clínico-qualitativa. Petrópolis: Vozes.

Warpechowski, A., \& Mosmann, C. (2012). A experiência da paternidade frente à separação conjugal: Sentimentos e percepções. Temas em Psicologia, 20, 247-260.

Recebido: $11 / 06 / 2012$ Última revisão: $17 / 12 / 2012$ Aceito: 04/01/2013

\section{Notas:}

1 A Psicologia está inserida no Núcleo desde 2005 através de um projeto de extensão desenvolvido em parceria com o local. Inicialmente a proposta era que os estagiários da Psicologia ficassem à disposição do serviço para auxiliar nas situações que tivessem envolvidos conflitos de família. Em 2007, o projeto ampliou as suas atividades, trabalhando além do plantão semanal com a proposta da mediação familiar.

2 Os pontos entre parênteses se referem à retirada de partes repetidas ou não relevantes para o tema abordado e os colchetes indicam algumas explicações da autora a fim de clarificar o texto ao leitor. 